\title{
Strength Characteristics of Compacted Fly Ash Treated Expansive Soil due to Wetting-Drying Cycles Repetition
}

\author{
Hasriana $^{1, *}$, Hamkah ${ }^{2}$, Melly Lukman ${ }^{3}$, Zubair Saing $^{4}$ \\ ${ }^{1}$ Department of Civil Engineering, Politeknik Negeri Ujung Pandang, Makassar, Indonesia \\ ${ }^{2}$ Department of Civil Engineering, Politeknik Negeri Ambon, Indonesia \\ ${ }^{3}$ Department of Civil Engineering, Universitas Kristen Indonesia Paulus (UKIP), Makassar, Indonesia \\ ${ }^{4}$ Department of Civil Engineering, Universitas Muhammadiyah Maluku Utara, Ternate, Indonesia
}

Received August 15, 2021; Revised September 28, 2021; Accepted November 2, 2021

\section{Cite This Paper in the following Citation Styles}

(a): [1] Hasriana, Hamkah, Melly Lukman, Zubair Saing, "Strength Characteristics of Compacted Fly Ash Treated Expansive Soil due to Wetting-Drying Cycles Repetition," Civil Engineering and Architecture, Vol. 9, No. 7, pp. 2117-2128, 2021. DOI: 10.13189/cea.2021.090701.

(b): Hasriana, Hamkah, Melly Lukman, Zubair Saing (2021). Strength Characteristics of Compacted Fly Ash Treated Expansive Soil due to Wetting-Drying Cycles Repetition. Civil Engineering and Architecture, 9(7), 2117-2128. DOI: 10.13189/cea.2021.090701.

Copyright $\bigcirc 2021$ by authors, all rights reserved. Authors agree that this article remains permanently open access under the terms of the Creative Commons Attribution License 4.0 International License

\begin{abstract}
Due to high swelling-shrinkage caused by climate change, expansive soil is a significant problem in light construction, road embankments, and slope stability (wet and dry). The physical and mechanical properties of the soil are affected by repeated drying and wetting cycles, particularly changes in volume, negative pore water pressure (suction), and compressive strength. Fly ash is used to increase soil strength and reduce plasticity caused by swelling to address this issue. Because of its chemical properties, fly ash is an excellent choice for low-cost soil improvement. The purpose of this investigation is to determine the static mechanical properties of expansive soil fly ash stabilization under Proctor standard compaction conditions. Mechanical properties were investigated due to changes in soil moisture content, saturation, suction, and compressive strength caused by repeated drying and wetting cycles. The soil's suction was measured using Whatman \#42 filter paper, and the soil's compressive strength was tested using a free compression test. According to the findings, the fly ash mixture altered the expansion and shrinkage behavior of expansive soils by lowering the consistency limit. At the same moisture content, the addition of $5 \%$ to $15 \%$ fly ash increases the compressive strength of the soil significantly. Compressive strength $(q u)$ and stress-strain modulus $(E i)$ decreased in 1-4 cycle cycles, and after four cycles, changes in compressive strength and stress-strain modulus were very small or insignificant. The proposed method effectively
\end{abstract}

reduces the loss of expansive soil strength caused by environmental changes (wetting-drying). As a result, it contributes significantly to the development of materials to reduce structural damage in expansive soils.

Keywords Expansive Soil, Unsaturated Soil, Fly Ash Stabilization, Wetting-Drying Cycles, Unconfined Compression Strength

\section{Introduction}

Expansive soil is one of the most common problems encountered in the civil engineering sector. The expansive soil issue has resulted in considerable losses, particularly in light structures or constructions and roads [1], [2]. In the United States, the losses caused by the expansive soil problem outnumber those caused by any other natural disasters, including earthquakes and tornadoes [3], [4]. In terms of soil distribution, expansive soils can be found throughout Indonesia, from North Sumatra to Papua [5], [6].

The soil in the tropics is constantly drying and wetting due to the alternating rainy and dry seasons. Repeated drying and wetting cycles will cause physical and mechanical properties to change [7]. Mixing fly ash with expansive clay is one method of chemical stabilization. 
The availability of this material rises in tandem with the number of PLTU developments that use coal as fuel [8].

Several previous studies on the effect of repeated drying-wetting on soil mechanical properties concluded that the number of repetitions of the drying-wetting cycle and the degree of drying affected the decrease in compressive strength. The compressive strength decreases as the number of repetitions of the drying-wetting cycle increases. However, after six cycles of six repetitions, the change in compressive strength did not show a significant change [9]-[12].

Meanwhile, the use of fly ash for soil improvement has proven to be highly effective [13]. The plasticity index, optimum moisture content, swelling rate, and swelling pressure increased as the proportion of bentonite increased and maximum dry density decreased. The more fly ash there is, the lower the plasticity index, density, swelling rate are, and swelling pressure. The optimal proportion of fly ash is $5 \%$, which significantly reduces the rate of swelling pressure. The addition of fly ash to swollen soil improves the engineering properties of the soil [14]. Another finding revealed that adding $20 \%$ fly ash to the clay significantly increased the soil's strength. Aside from fly ash, many studies have been conducted to improve the strength of expansive soils using other additives. The addition of cement kiln dust (CKD) raises the soil properties index. The addition of $10 \%$ CKD significantly increased the soil's compressive strength and bearing capacity (CBR). Expansive soil improvement with CKD can improve the subgrade of lightly travelled roads and as an admixture in lime stabilization during the construction of flexible pavements on expansive soils [2]. Furthermore, various additives to improve expansive soils' strength and bearing capacity have been extensively researched and well documented [15]-[18].

Based on previous studies on the improvement of expansive soils as a guide, this study determined the characteristics of the compressive strength of expansive soils by stabilizing fly ash on the behaviour of environmental changes by modelling repeated wetting-drying. As a result, the objective of this study is to investigate the effect of adding fly ash on soil plasticity and strength, specifically the negative pore-water pressure and compression strength of the compacted expansive soil due to wetting-drying cycle repetition. The study's findings provide a comprehensive overview of expansive soil properties stabilized with fly ash as an alternative construction material and contribute to the future advancement of material engineering technology.

\section{Materials and Methods}

\subsection{Expansive Clay}

The expansive clay in this study was obtained from Tabona, Ternate City, with the sampling point located at $0^{\circ} 46^{\prime} 33$ "N and $127^{\circ} 43^{\prime} 21$ "E, as shown in Figure 1. Following that, the clay was mixed with commercially available Bentonite to produce a moisture content of $198 \%$, indicating that the mixed soil has high plasticity according to the unified soil classification system (USCS) [7]. Fly ash obtained from the Tidore power plant was added at a rate of $5 \%$ to $15 \%$, depending on the weight ratio.

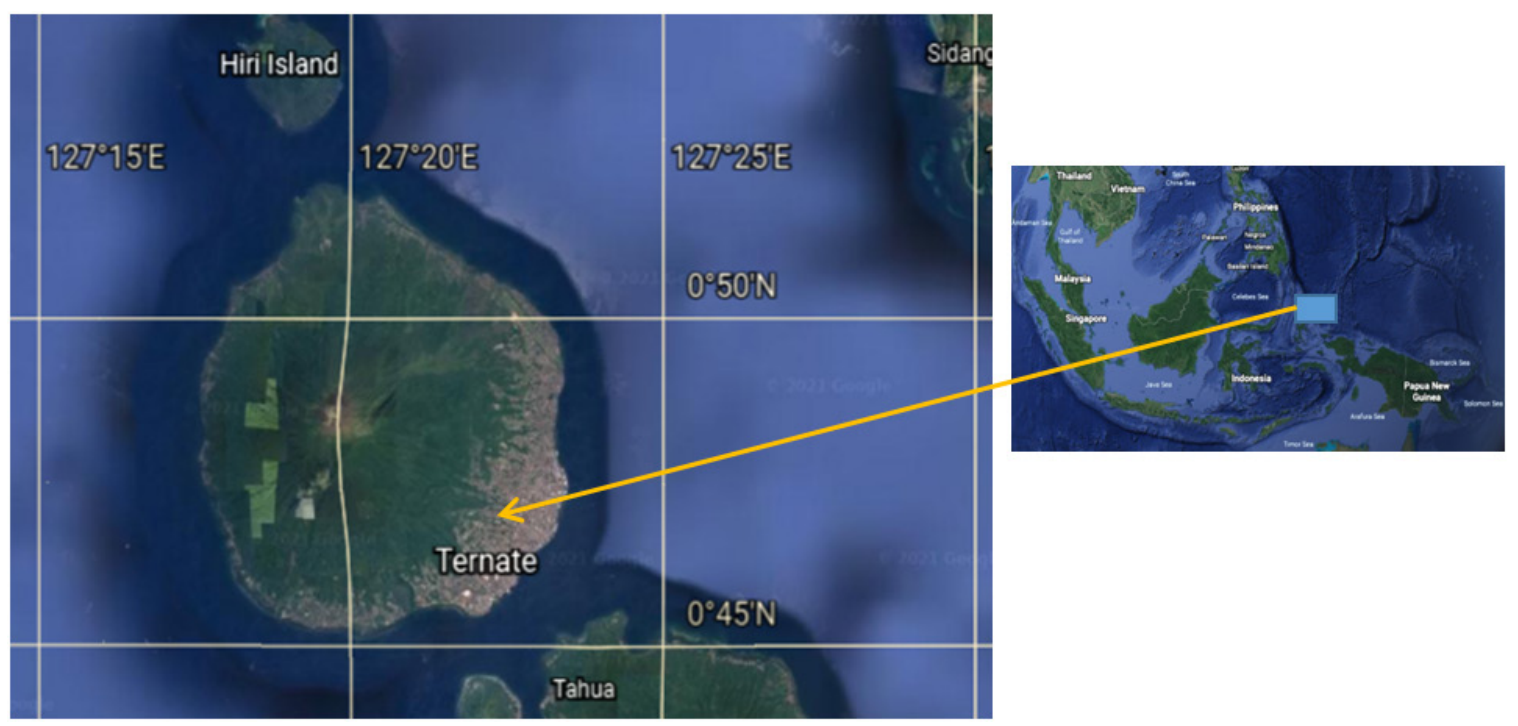

Figure 1. Clay soil sampling location 


\subsection{Sample Preparation}

Before the pulverization process, the clay soil is dried in air-dry conditions. To make a clay-bentonite mixture, first, weigh the required amount of clay and bentonite with the total dry weight of the sample and mix it in a dry state. Water is added to the soil mixture to achieve the best moisture content for compaction results. Manual mixing is used to homogenize the mixture. At each stage of mixing, to achieve a homogeneous mixture. The mixture's water content was determined using the Standard Proctor ASTM D 698 (1995) test results [19]. The drying-wetting experiment is repeated on a cylindrical sample with a diameter of $36.5 \mathrm{~cm}$ and a height of $12 \mathrm{~cm}$ created with a PVC mold.

\subsection{Atterberg Limits and Compaction Tests}

The soil consistency of clay and mixed soils was determined, and the liquid and plastic limits were tested under ASTM D 4318 (1995) [19]. The optimum moisture content was determined according to the standard Proctor following ASTM D 698 (1995) [19], to prepare the sample for the wetting-drying cycle test.

\subsection{Wetting-Drying Cycle Test}

This test is used to determine how mixed soils' physical and mechanical properties change. Before testing, all samples were kept for 24 hours. This procedure entails lowering and raising the percentage of water until it reaches a predetermined level of water content. The water content is reduced from the optimum moisture content to a dry content of $25 \%, 50 \%, 75 \%$, and $100 \%$ (drying path), and the water content is added from the dry water content to the optimum moisture content (wetting path). The entire procedure was repeated six times. Previous studies found no difference test results after the fifth drying-wetting cycle [20]-[23]. Table 1 and Figure 2 summarize the drying-wetting process model for all compacted samples, modified based on previous studies findings [7], [12].

Table 1. The drying-wetting process of soil samples

\begin{tabular}{|c|c|c|c|c|c|c|c|c|c|c|}
\hline \multirow{4}{*}{ Process stages } & \multicolumn{10}{|c|}{ Drying-Wetting (Compacted Initial Condition) $w_{i}=w_{\text {opt }}$} \\
\hline & \multicolumn{10}{|c|}{ Kadar air } \\
\hline & \multicolumn{2}{|c|}{ Wopt } & \multicolumn{2}{|c|}{$25 \%$} & \multicolumn{2}{|c|}{$50 \%$} & \multicolumn{2}{|c|}{$75 \%$} & \multicolumn{2}{|c|}{$100 \%$} \\
\hline & $5 \% \mathrm{FA}$ & $15 \% \mathrm{FA}$ & $5 \% \mathrm{FA}$ & $15 \% \mathrm{FA}$ & $5 \% \mathrm{FA}$ & $15 \% \mathrm{FA}$ & $5 \% \mathrm{FA}$ & $15 \% \mathrm{FA}$ & $5 \% \mathrm{FA}$ & $15 \% \mathrm{FA}$ \\
\hline Drying (\%) & 26,8 & 23,7 & 20,1 & 17,8 & 13,4 & 11,8 & 6,7 & 5,9 & 0 & 0 \\
\hline Wetting (\%) & 0 & 0 & 6,7 & 5,9 & 13,4 & 11,8 & 20,1 & 17,8 & 26,8 & 23,7 \\
\hline
\end{tabular}

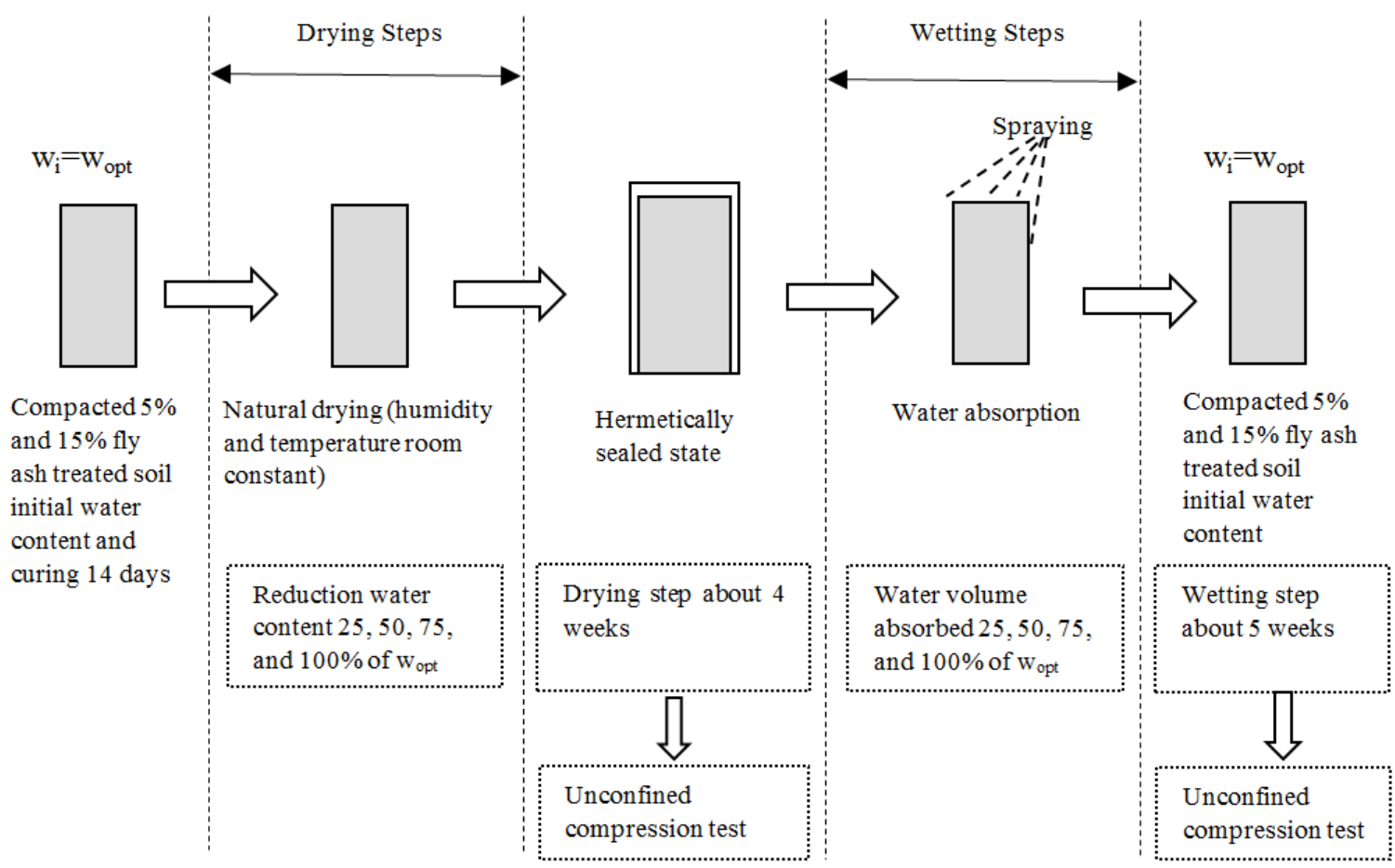

Figure 2. Dry-wetting repeat experimental test (modified after Maekawa and Miyakita, 1991; Saing, et al., 2020) 


\subsection{Soil Suction Measurement Method}

Whatman \#42 filter paper was used to measure negative pore pressure (suction). When compared to other methods, this method has a relatively broad measurement range. To avoid contamination of each coated filter paper on the top and bottom, three filter papers with a diameter of $2.7 \mathrm{~cm}$ and placed on the top, middle, and bottom fitted on each sample. The water content of the filter paper and thus the value of soil suction are calculated using a calibration graph [24]-[27].

\section{Results and Discussions}

\subsection{Physical Characteristics and Soil Density}

Table 2 shows the results of testing the physical properties of the expansive soil (clay + Bentonite) mixed with $5 \%$ and $15 \%$ fly ash. Figure 3 depicts the results of the Scanning Electron Microscopy (SEM) test, which included photos of the soil microstructure, while Figure 4 depicts the results of the static compaction test using the standard Proctor method.

Table 2. Summary of test results of basic soil properties

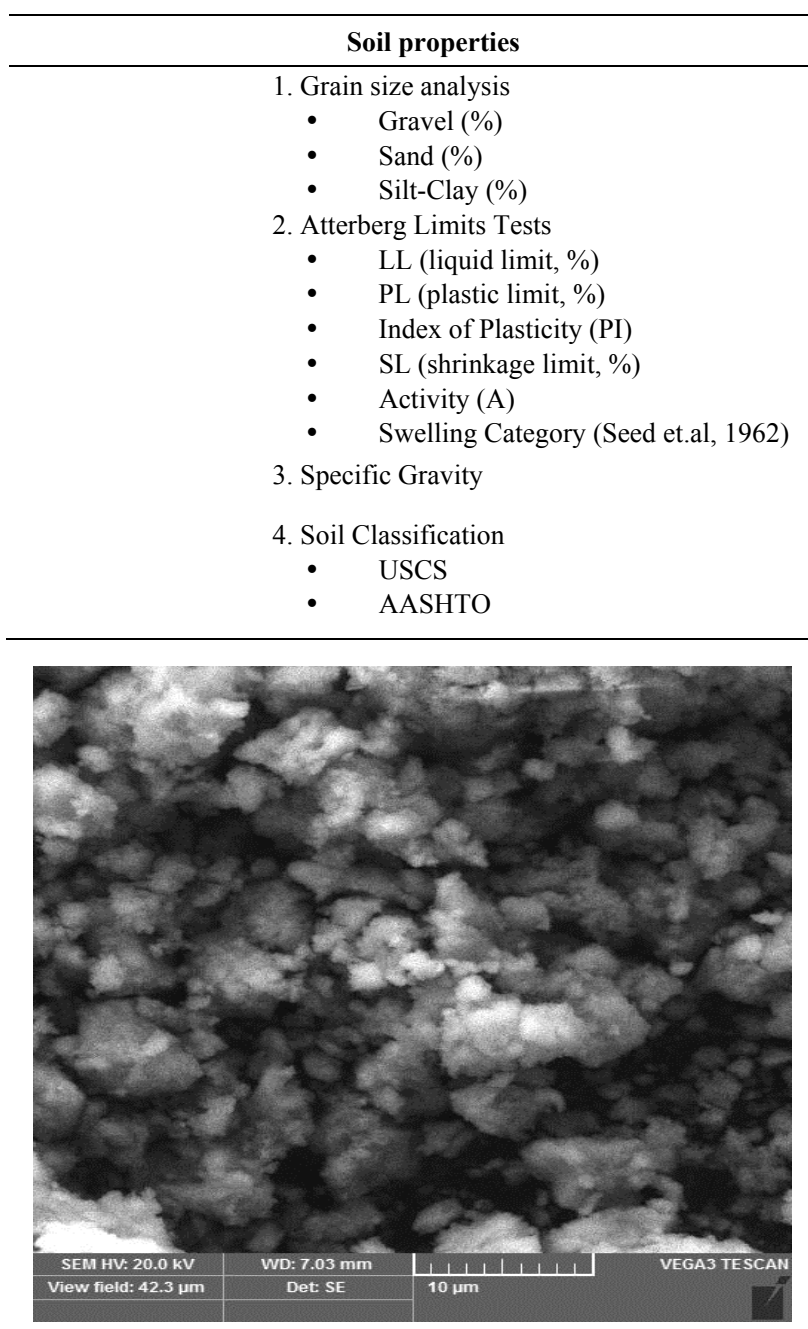

a

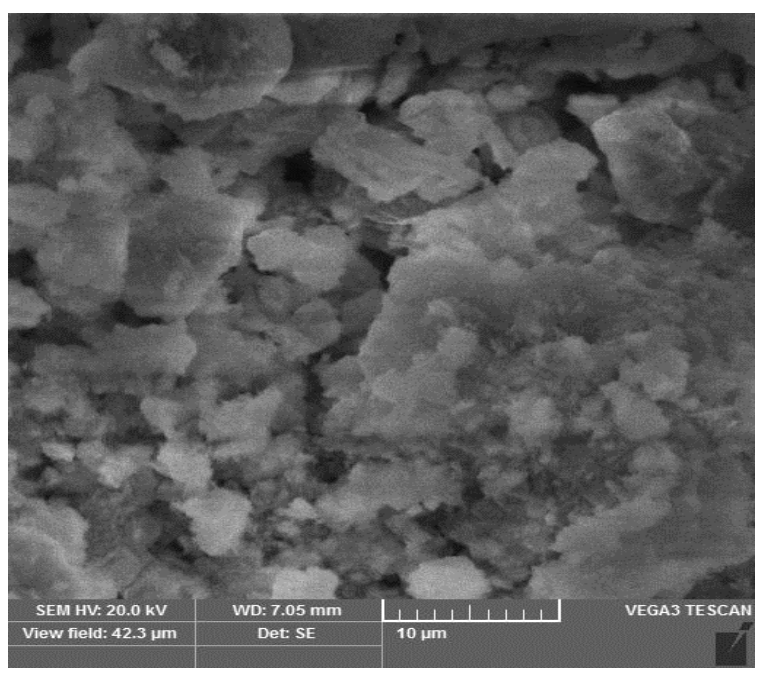

b

Figure 3. Microphotograph of soil: a) Fly ash treated soil; b) untreated soil 


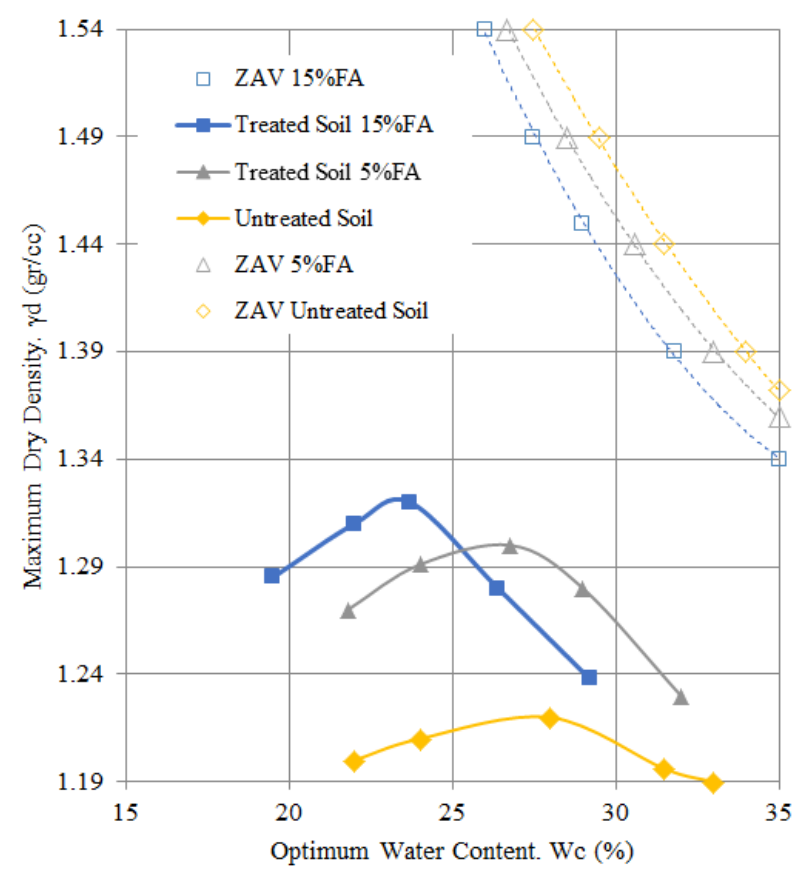

Figure 4. Proctor standard test results

Compaction of clay (expansive), mixed clay with 5\% and $15 \%$ fly ash with standard Proctor produces compaction curves like the one shown in Figure 4, which shows the relationship between water content and the dry volume or density of the soil. The compaction process is designed to achieve a maximum dry density with the least amount of moisture. The dry density of the expansive clay with $5 \%$ fly ash was $1.3 \mathrm{~g} / \mathrm{cc}$ at the optimum moisture content of $26.8 \%$, while the dry density of the expansive clay with $15 \%$ fly ash was $1.32 \mathrm{~g} / \mathrm{cc}$ at the optimum water content of $23.7 \%$. The addition of FA above $15 \%$ increased the dry density of the soil while decreasing the optimum water content. The condition is influenced by the chemical composition of fly ash and $\mathrm{CaO}$ hydration events, resulting in a decrease in water content and an increase in dry density.

The physical and mechanical properties of the soil are affected by compaction moisture content [28], [29]. Figure 4 depicts compacted clay's physical characteristics, including its composition or micro-macro structure, plasticity, and density. At the same time, its shear strength and permeability properties can express its mechanical characteristics.

Figure 5 depicts the relationship between the density level, volume change, and negative pore pressure (suction) of the soil. The density and volume of the large pores decrease, causing the void ratio to rise when the water content exceeds the optimum level. At the same moisture content, treated $15 \%$ fly ash is smaller than untreated $5 \%$ fly ash and smaller than the original soil. The soil becomes denser with the addition of $15 \%$ fly ash, resulting in a smaller pore volume and a decrease in pore number (Figure 5A). Furthermore, the negative pore-water pressure decreases (Figure 5B). When fly ash was mixed with $\mathrm{CaO}$, the chemical composition of the fly ash, particularly alumina and active silica, influenced the suction change.

Figures 5C and 5D show that the expansive soil curve has a linear shape with the same slope. The curve shape is linear for $5 \%$ fly ash with a slope of $56^{\circ}$ to a degree of saturation $(\mathrm{Sr})$ of $70 \%$; above $70 \%$, the slope changes to $25^{\circ}$. Meanwhile, the curve is linear for a $15 \%$ FA mixture with a slope of $60^{\circ}$ and a saturation degree of $65 \%$. The slope changed to $23^{\circ}$ when the degree of saturation exceeded $65 \%$, owing to the addition of fly ash at the same water content, which increased the degree of saturation. Furthermore, the addition of $15 \%$ FA resulted in higher pore water pressure due to the lower water content (Figure 5E).

Natural clay has a maximum dry density of $1.2001 \mathrm{~g} / \mathrm{cc}$ at an optimum moisture content of $28 \%$ and a suction value of $4500 \mathrm{kPa}$ [7], whereas expansive soil mixed with $5 \%$ FA has a maximum dry density of $1.3 \mathrm{~g} / \mathrm{cc}$ at an optimum moisture content of $28 \%$ and a suction value of $15,615.47 \mathrm{kPa}$. It also has a $15 \% \mathrm{FA}$ of $1.32 \mathrm{gr} / \mathrm{cc}$ at $23.7 \%$ optimum water content and suction of $1046.08 \mathrm{kPa}$. As a result, the addition of $15 \%$ FA results in a higher maximum density and a higher negative pore water pressure but a lower optimum water content than the addition of 5\% FA (Figure 5E and 5F). 

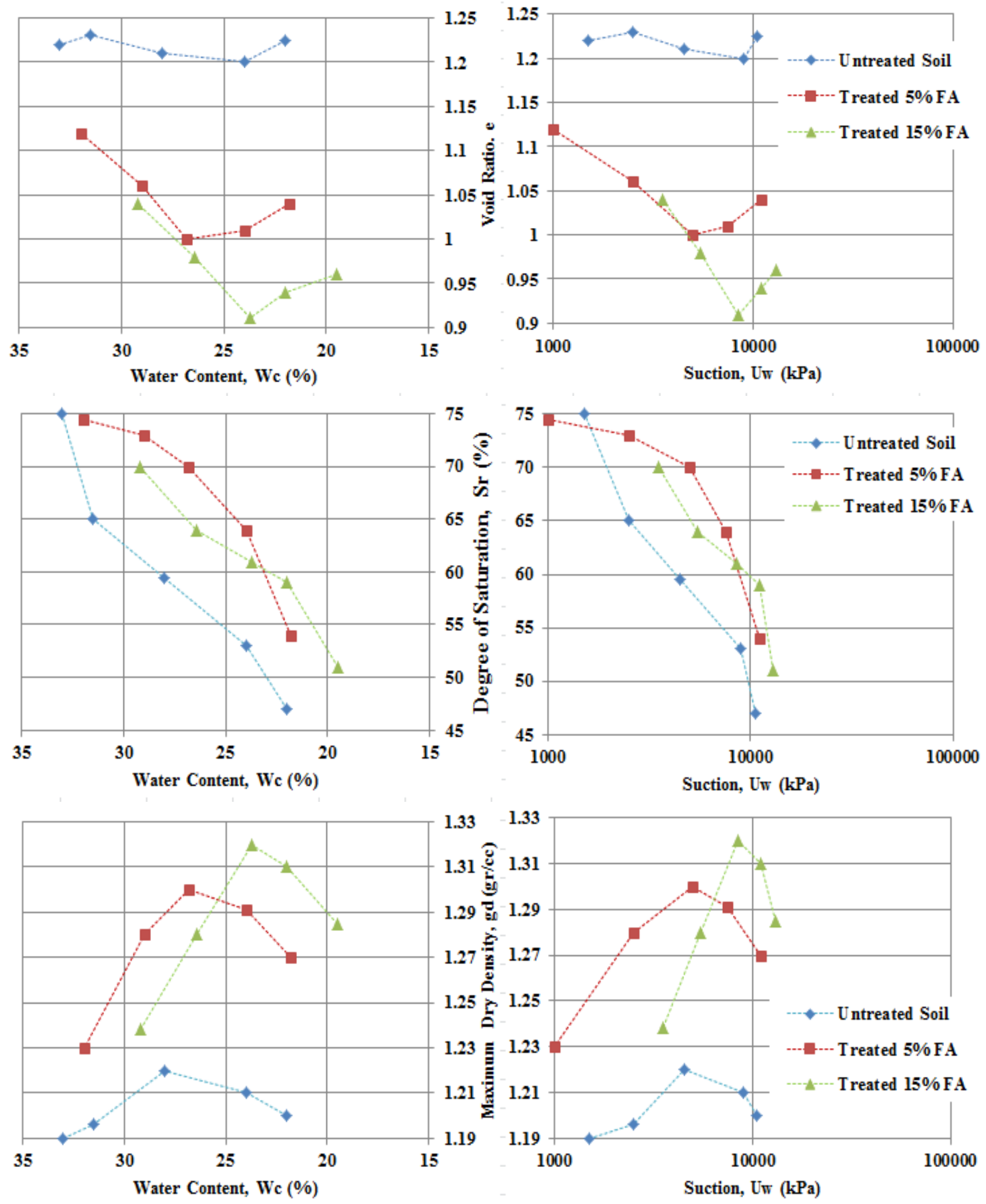

Figure 5. Relationship of water content (w), void ratio (e), degree of saturation ( $\mathrm{Sr}$ ), and stress 


\subsection{Change in Compressive Strength (qu) of $5 \%$ FA Treated Soil due to Repeated Drying-Wetting Cycle}

Figure 6 presents the changes in compressive strength (qu) of expansive soil mixed with 5\% FA as the water content decreased due to repeated drying (drying path).

However, as shown in Figure 6, the compressive strength of the soil increases with each cycle; in drier soil conditions (water content less than $40 \%$ ), the compressive strength of the soil increases significantly. The soil compressive strength decreased significantly and gradually decreased after four drying cycles because of the repeated drying cycles. Several previous studies using different methods and soil types concluded that the decrease in soil compressive strength after the fourth cycle is negligible. Previous research has discovered that as the number of drying cycles increases, the bleach concentration decreases [7], [11], [12], [23]. The increased soil saturation $(\mathrm{Sr})$ due to the cycle's repetition caused this decrease.

Furthermore, Figure 7 represents the change in compressive strength of the expansive soil $+5 \%$ FA due to repeated wetting cycles (wetting path). Following Figure 7 , the decrease in compressive strength caused by repeated wetting cycles is not too significant, especially at water content levels above $40 \%$. When the water content is less than $30 \%$, the compressive strength of the soil is lower than during the drying process. The soil's degree of saturation ( $\mathrm{Sr}$ ) changes, then the soil compressive strength decreases as the number of cycles increases. The soil void ratio decreases, causing soil density to increase and the soil strength to increase. Previous research has also discovered that higher density produces more clay particles with parallel and parallel orientations under certain water content conditions, resulting in more excellent soil structure dispersion [30], [31].

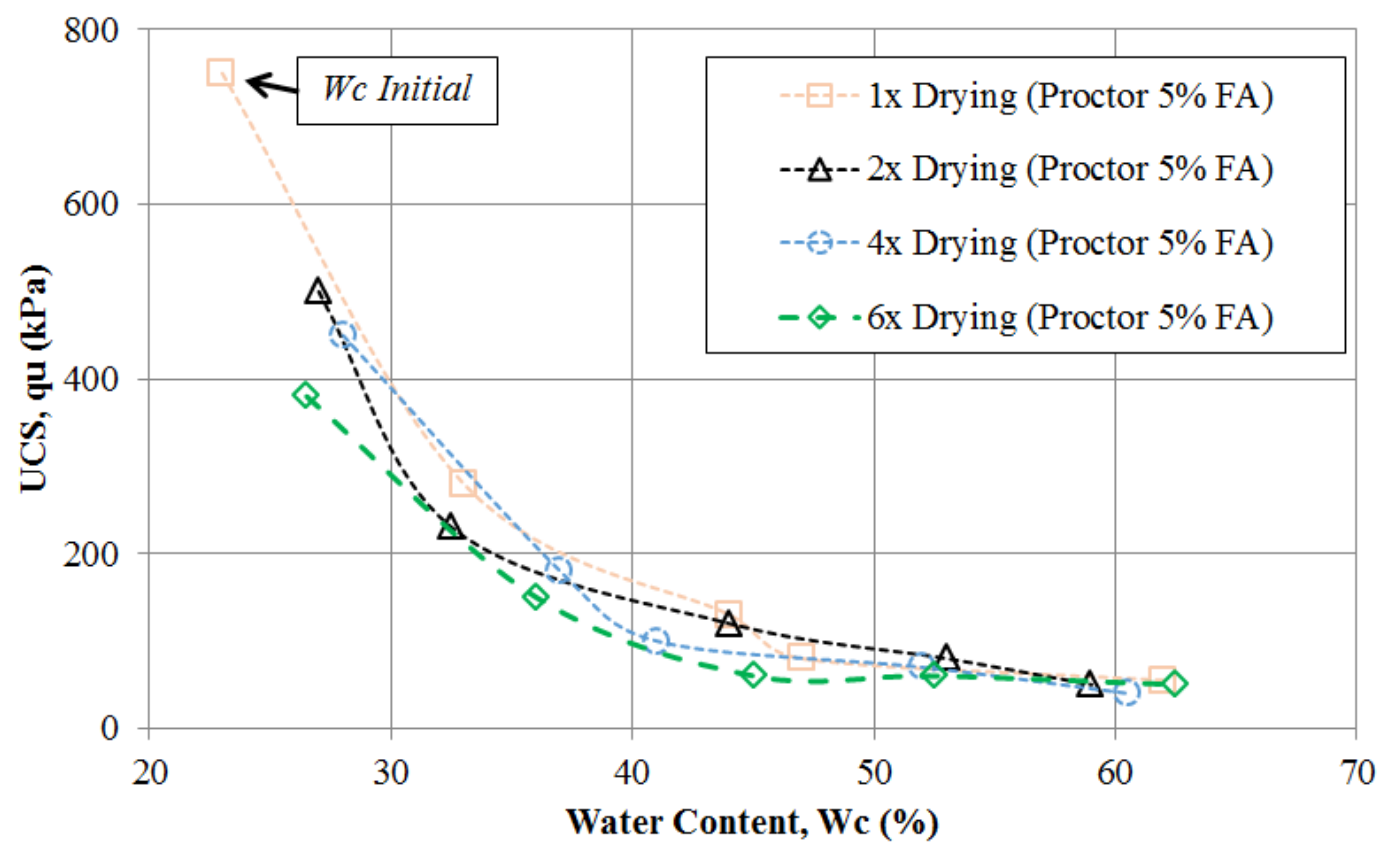

Figure 6. Compressive strength of 5\% FA treated soil on drying path 


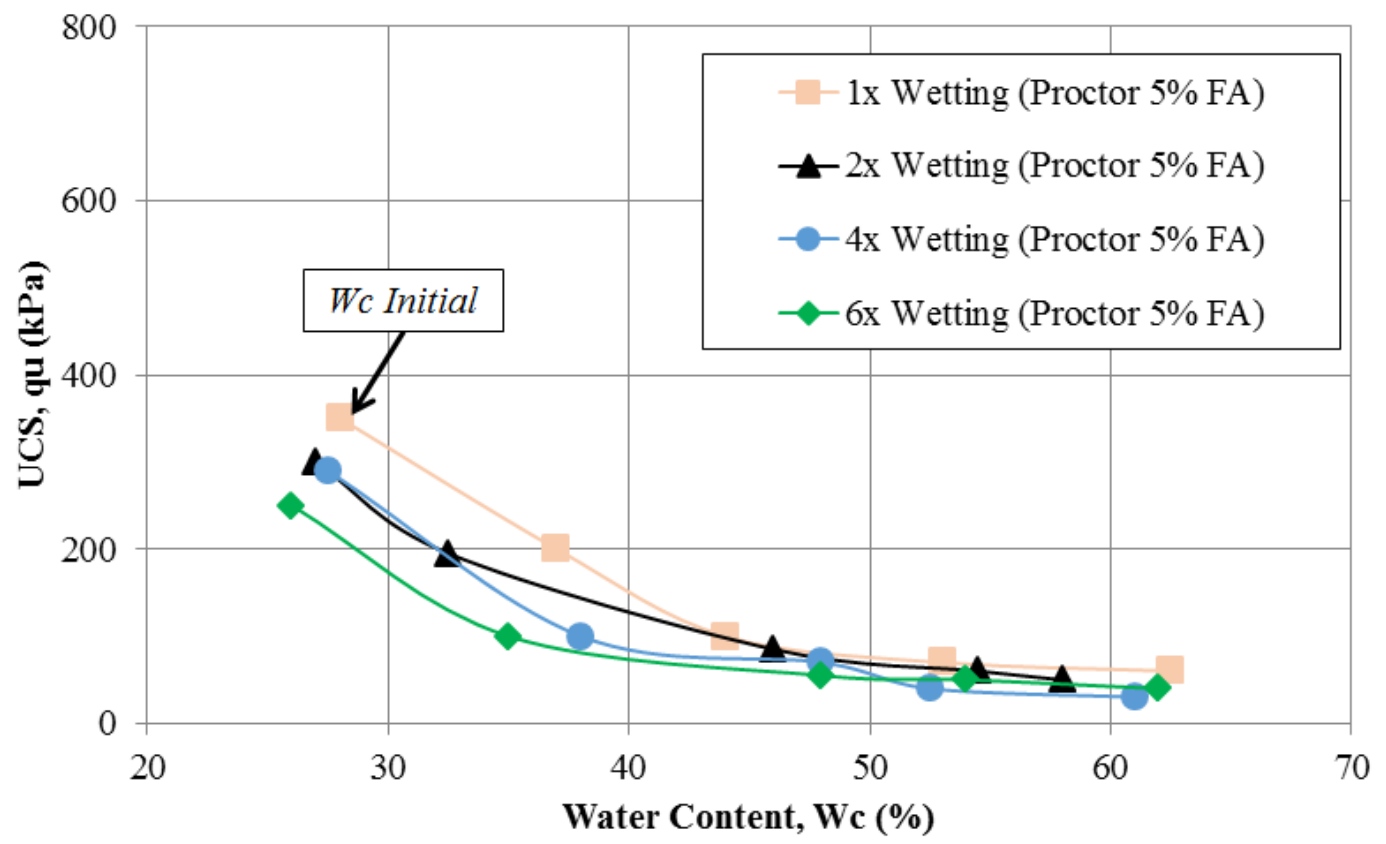

Figure 7. Compressive strength of $5 \%$ FA treated soil on wetting path

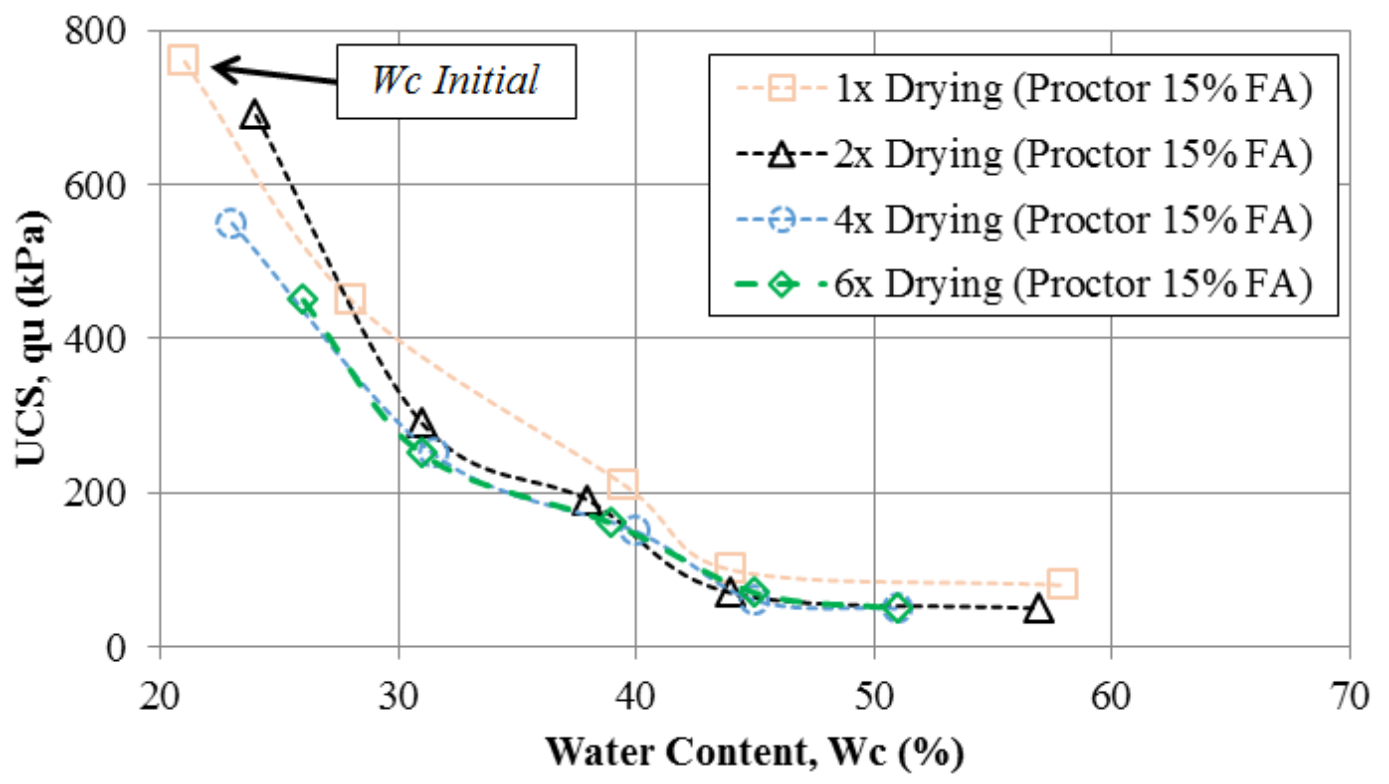

Figure 8. Compressive strength of $15 \%$ FA treated soil on drying path

\subsection{Change in Compressive Strength ( $q u)$ of $15 \%$ FA} Treated Soil due to Repeated Drying-wetting Cycle

Figures 8 and 9 represent the change in compressive strength of the expansive soil with the addition of $15 \%$ FA due to repeated drying and wetting cycles.

Based on the data, the expansive soil with $15 \%$ FA has higher compressive strength and a smaller particle structure than the mixed soil with 5\% FA. With its lower water content and smaller pore volume, this soil is more stable. This condition is thought to be caused by the chemical composition of fly ash, which functions to reduce water content and improve soil physical properties due to $\mathrm{CaO}$ hydration, where the mixed $\mathrm{CaO}$ content of $15 \%$ FA exceeds $5 \%$ FA. 


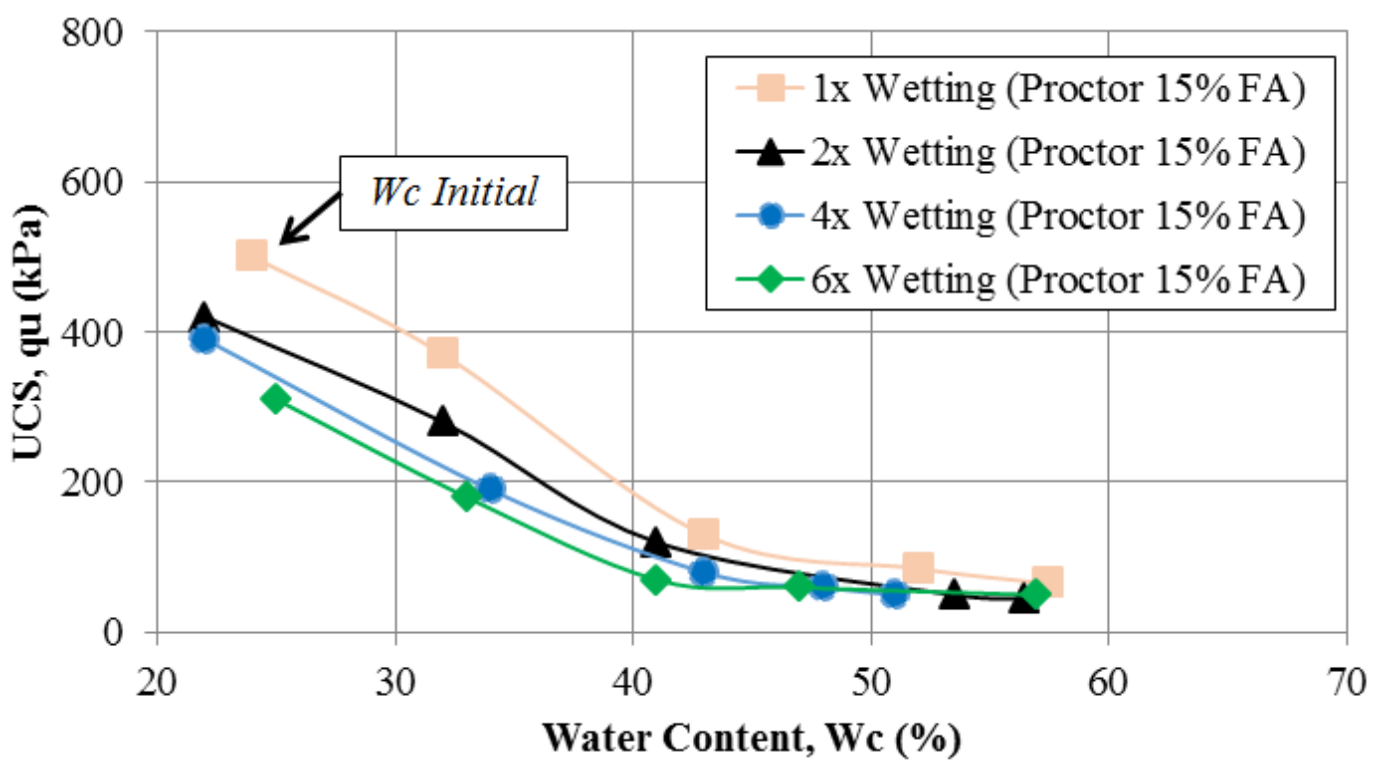

Figure 9. Compressive strength of $15 \%$ FA treated soil on wetting path

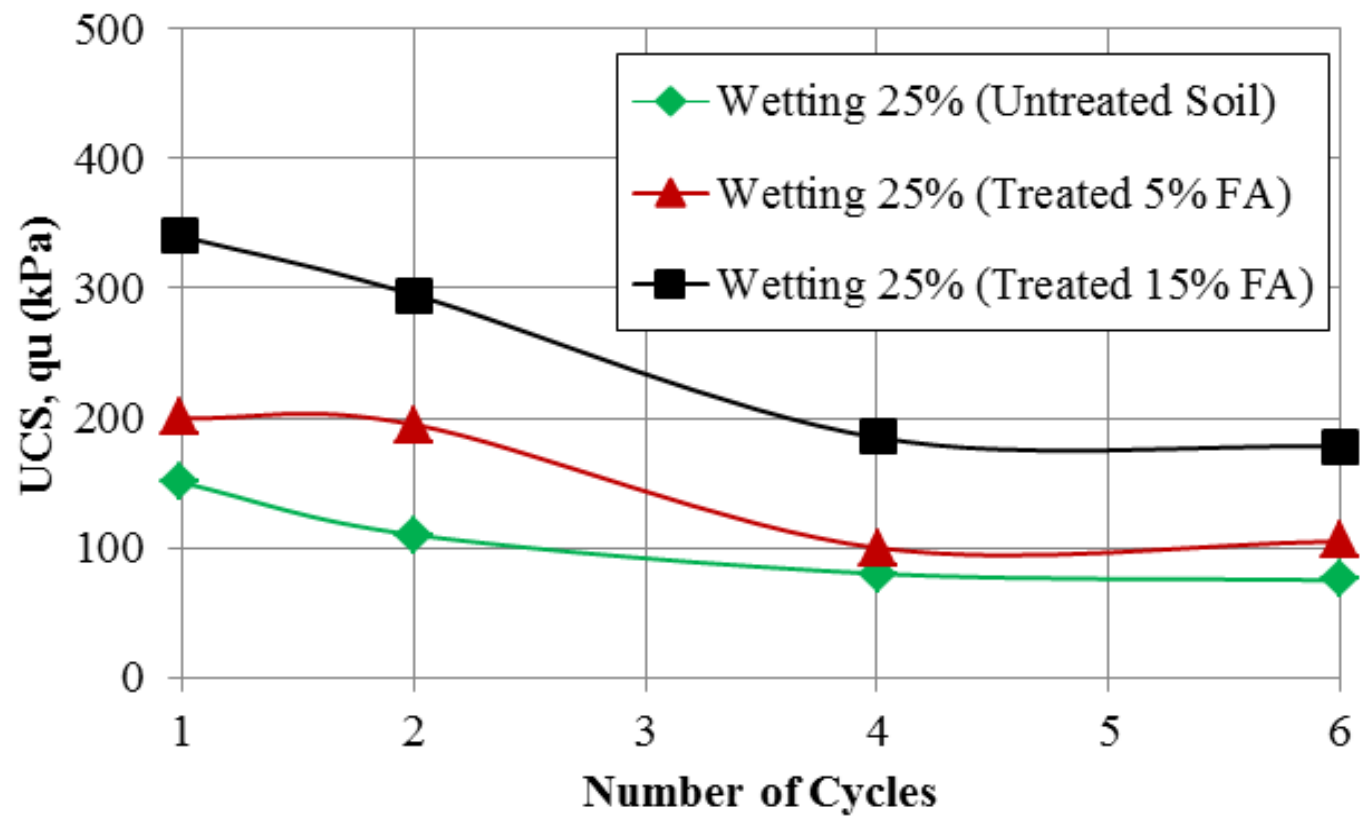

Figure 10. The compressive strength $(q u)$ vs number of wetting cycles $25 \%$

\subsection{The Compressive Strength ( $q u)$ and Stress-Strain Modulus ( $\mathrm{Ei}$ ) Changes to the Number of Wetting Paths of $25 \%, 50 \%$, and $100 \%$}

The relationship between the compressive strength ( $q u)$ and the stress-strain modulus on the number of cycles on the Proctor specimen with 25\% wetting shows in Figure 10 and 11.

Based on Figs. 10 and 11, it is clear that the expansive clay soil experienced a $26 \%$ decrease in soil compressive strength $(q u)$ and a $2 \%$ decrease in soil stress-strain modulus $(E i)$ in 1-2 cycles, a $28 \%$ decrease of compressive strength, and a $19 \%$ decrease of $E i$ in 2-4 cycles, while no visible compressive strength change at 4-6 cycles.

Furthermore, a 5\% FA mixed soil exhibits minimal compressive strength and stress-strain modulus for 2-4 times cycles. The compressive strength $(q u)$ decreases by $47 \%$, and $E i$ decreases by $25 \%$. The number of cycles is between 4-6 times, and the compressive strength value is close to constant. Meanwhile, for mixed soil $15 \%$ FA, the decrease in strength for $1-2$ times cycles is $14.5 \%$, in cycles of 2-4 times, the decrease in compressive strength $(q u)$ is $38 \%$ and $E i$ is $28 \%$, while for 4-6 times cycles the $q u$ and Ei are deficient. 


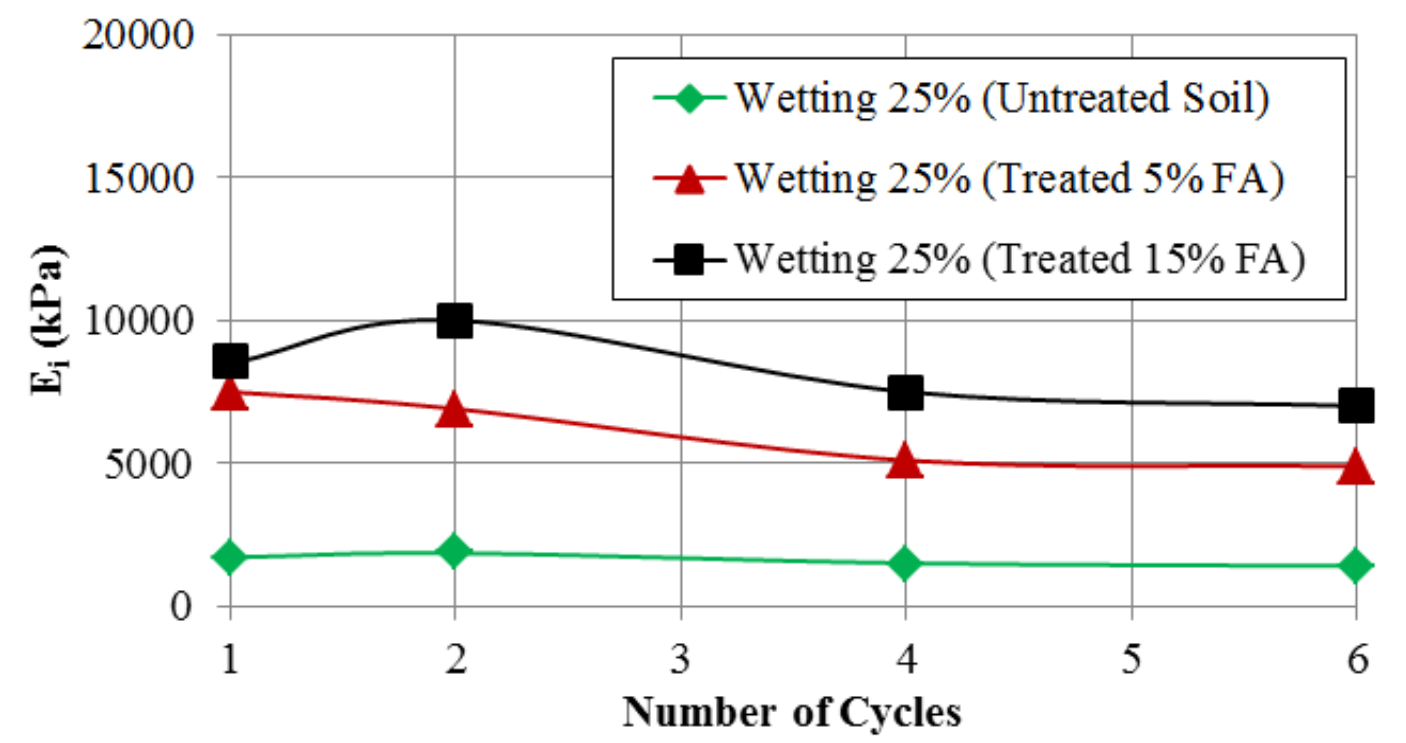

Figure 11. The stress-strain modulus ( $E i)$ changes vs number of wetting cycles $25 \%$
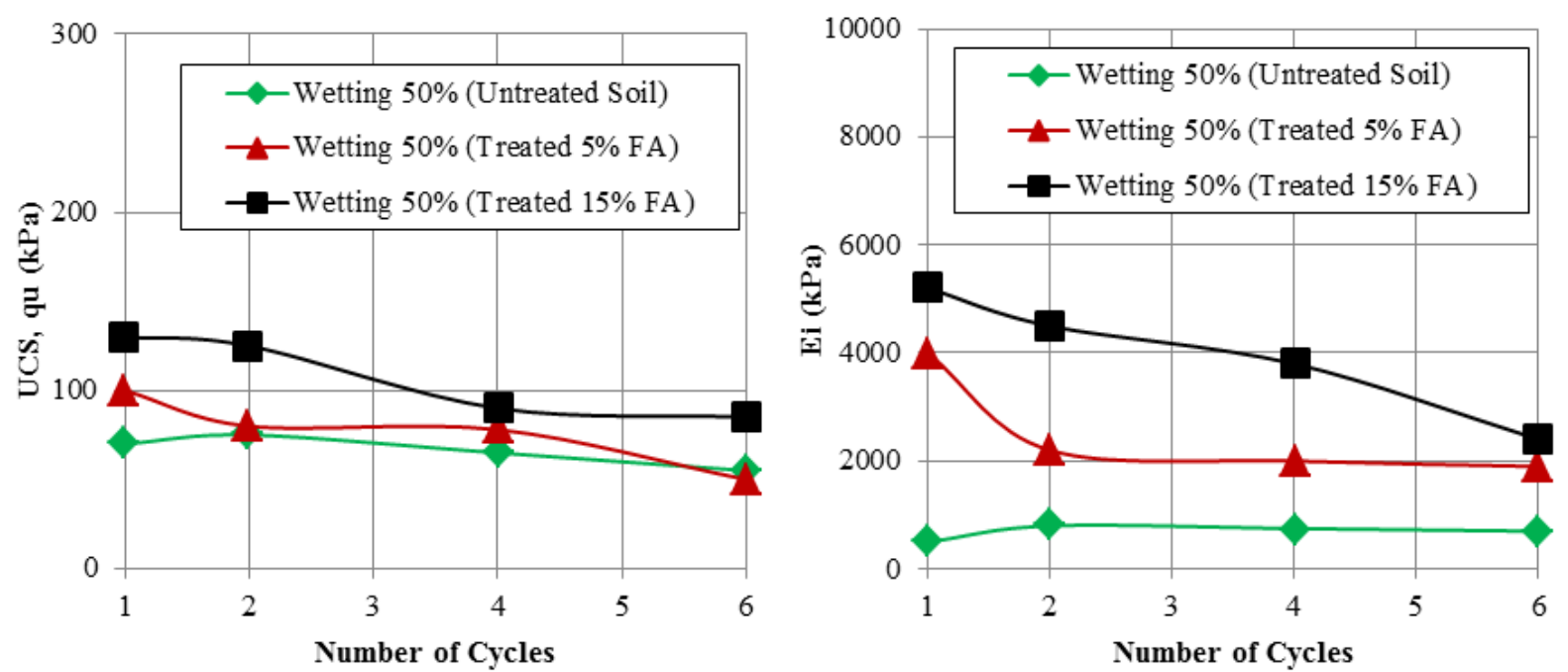

Figure 12. The compressive strength $(q u)$ and stress-strain modulus $(E i)$ changes to the number of wetting cycles $50 \%$

The changes of $q u$ and $E i$ during the $50 \%$ wetting cycle represents in Figure 12. Based on the figures, it is clear that the increase of compressive strength and stress-strain modulus in cycles of 1-6 times is very small or insignificant.

Meanwhile, the 5\% FA mixture reduced compressive strength by $18 \%$ and stress-strain modulus by $42 \%$ in $1-2$ cycles, but the $q u$ and $E i$ change was very small or insignificant in 2-6 cycles. Furthermore, in cycles 1-2, the $15 \%$ FA compressive strength decreased by $18 \%$, and $\mathrm{Ei}$ decreased by $42 \%$, and in cycles $2-4$, it decreased by $30 \%$, and the stress-strain modulus was $17 \%$, but the change was minimal after cycle 4 .

The compressive strength $(q u)$ and stress-strain modulus (Ei) change to $100 \%$ wetting on compacted untreated and treated with $5 \%$ and $15 \%$ fly ash are shown in Figure 13. The figure shows that the soil $q u$ and $E i$ did not change during cycles 1-6. Compressive strength and stress-strain modulus decreased by $33 \%$ in $1-2$ cycles, $30 \%$ in $2-4$ cycles, and $60 \%$ in $4-6$ cycles, respectively, with compressive strength decreasing insignificantly in 4-6 cycles. Meanwhile, after 1-2 cycles, the mixed soil was $15 \% \mathrm{FA}$, the compressive strength was $41 \%$ lower, and the stress-strain modulus was $42 \%$ lower. The compressive strength of the soil should not decrease as the void ratio and dry density decrease [32], [33]. It was thought to be because water trapped in soil peds is difficult to escape, increasing the degree of saturation and decreasing compressive strength $(q u)$ and stress-strain modulus. Furthermore, after 2-4 cycles, the compressive strength and stress-strain modulus increase as the void ratio decreases and the soil strain decreases, making water entry into the soil grains more difficult [7], [12], [23]. 

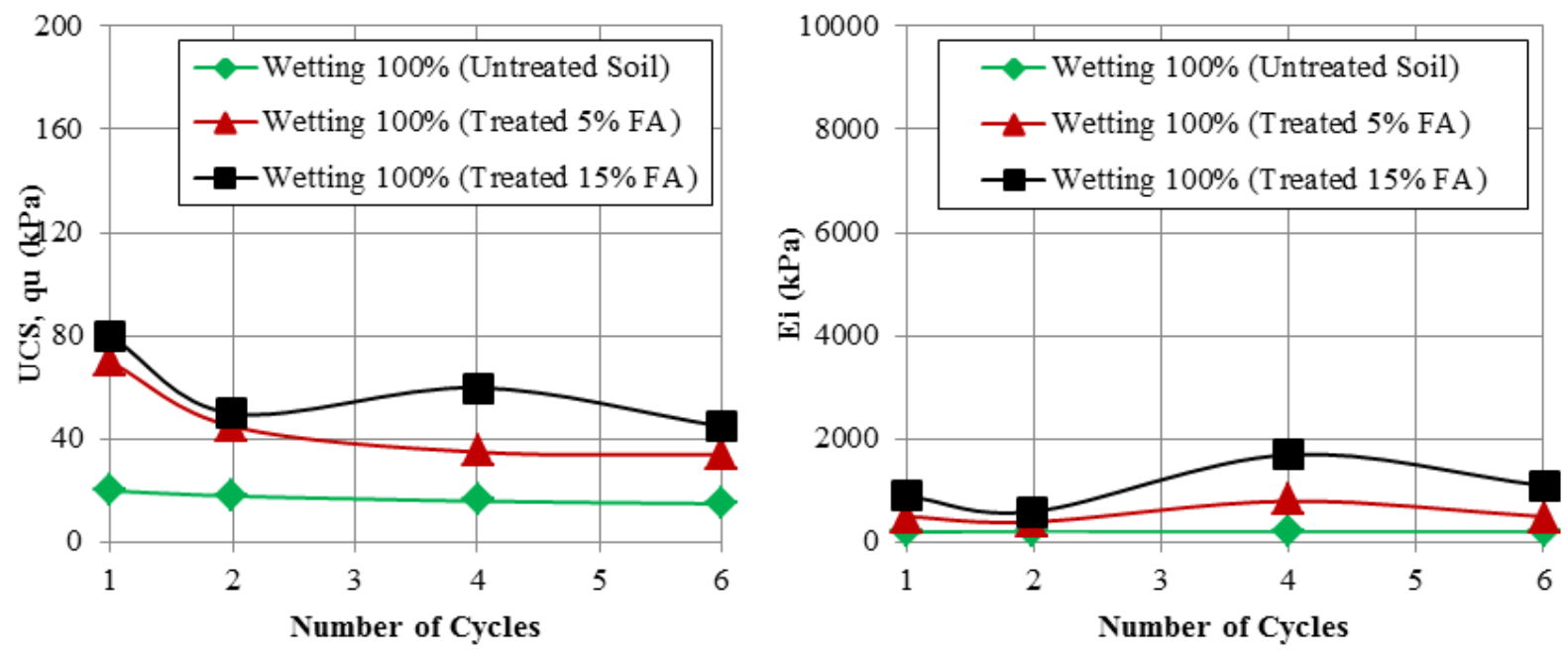

Figure 13. The compressive strength ( $q u$ ) and stress-strain modulus ( $E i)$ changes to the number of wetting cycles $100 \%$

\section{Conclusions}

Laboratory tests on the compressive strength changes of flay ash stabilized expansive soil were carried out, and the results are summarized below. The compressive strength characteristics of the soil are significantly influenced by repeated drying and wetting cycles. The compressive strength of the soil appears to decrease as the drying-wetting cycle is repeated, although the soil density increases and the void ratio decreases. When soil is compacted, the saturation level rises, and the void ratio falls, resulting in this situation. The soil compaction that occurs during the wetting-drying process does not allow the water to escape completely, so much water is trapped in the soil ped and reduces the compressive strength of the soil. Compressive strength (qu) and stress-strain modulus (Ei) tend to decrease in the first 1-4 cycles, and changes cease to be significant after the fourth cycle. As a result, the proposed method effectively reduces the decrease in expansive soil strength caused by environmental changes (wetting-drying), contributing significantly to material development to reduce structural damage caused by soil swelling-shrinkage.

\section{Acknowledgments}

The authors would like to express their gratitude and appreciation to Universitas Muhammadiyah Maluku Utara, Politeknik Negeri Ambon, UKIP Makassar, and Politeknik Negeri Ujung Pandang for their assistance and support throughout this research. We also appreciate and thank everyone who assisted us with the research and writing of this article. We also want to thank everyone who reviewed the work and offered suggestions, feedback, and corrections to make it better.

\section{REFERENCES}

[1] Y. Cheng, S. Wang, J. Li, X. Huang, C. Li, and J. Wu, "Engineering and mineralogical properties of stabilized expansive soil compositing lime and natural pozzolans," Constr. Build. Mater., vol. 187, pp. 1031-1038, 2018, doi: 10.1016/j.conbuildmat.2018.08.061.

[2] A. B. Salahudeen, A. O. Eberemu, and K. J. Osinubi, "Assessment of Cement Kiln Dust-Treated Expansive Soil for the Construction of Flexible Pavements," Geotech. Geol. Eng., vol. 32, no. 4, pp. 923-931, 2014, doi: 10.1007/s10706-014-9769-0.

[3] K. Faezehossadat and B. Jeff, "Expansive Soil: Causes and Treatments," i-manager's J. Civ. Eng., vol. 6, no. 3, p. 1, 2016, doi: 10.26634/jce.6.3.8083.

[4] J. A. Gobena and S. Suppiah, "Strength Characteristics of Tropical Expansive Soil-A Review," Int. J. Sci. Technol. Res., vol. 8, no. 7, pp. 710-715, 2019.

[5] Y. Zaika, A. Rachmansyah, and Harimurti, "Geotechnical behaviour of soft soil in East Java, Indonesia," IOP Conf. Ser. Mater. Sci. Eng., vol. 615, no. 1, 2019, doi: 10.1088/1757-899X/615/1/012043.

[6] A. T. Sudjianto, K. B. Suryolelono, A. Rifa, and I. B. Mochtar, "The Effect of Water Content Change and Variation Suction in Behavior Swelling of Expansive Soil," no. June, 2011.

[7] Z. Saing, M. H. Ibrahim, and Irianto, "Volume change and compressive strength of compacted lateritic soil under drying-wetting cycle repetition," Int. J. GEOMATE, vol. 19, no. 74 , pp. $75-82$, 2020, doi: 10.21660/2020.74.49473.

[8] M. Mollamahmutoglu, Y. Yilmaz, and A. G. Güngör, "Effect of a Class C Fly Ash on the Geotechnical Properties of an Expansive Soil," Uluslararası Mühendislik Araştırma ve Geliştirme Derg., vol. 1, no. 1, pp. 1-6, 2009.

[9] M. Muntaha, R. A. A. Soemitro, and D. D. Warnana, "The static and dynamic characteristic of undisturbed residual soils under drying-wetting cycle's repetition," 15th Asian Reg. Conf. Soil Mech. Geotech. Eng. ARC 2015 New Innov. Sustain., pp. 591-594, 2015, doi: 10.3208/jgssp.INA-04. 
[10] M. Y. Durgun, "Effect of wetting-drying cycles on gypsum plasters containing ground basaltic pumice and polypropylene fibers," J. Build. Eng., vol. 32, no. September, p. 101801, 2020, doi: 10.1016/j.jobe.2020.101801.

[11] M. Muntaha, "The effect of drying-wetting cycle's repetition to the characteristic of natural and stabilization residual soils jawa timur - Indonesia," IOP Conf. Ser. Mater. Sci. Eng., vol. 267, no. 1, 2017, doi: 10.1088/1757-899X/267/1/012030.

[12] H. Maekawa and K. Miyakita, "Effect of Repetition of Drying and Wetting on Mechanical Characteristics of A Diatomaceous Mudstone," Soils Found., vol. 31, no. 2, pp. 117-133, 1991.

[13] B. Bhagowati and N. Borthakur, "Impact of Cyclic Wetting-Drying Cycle on Swelling Behaviour of Lime And Fly Ash Stabilized Expansive Soil,” 2015.

[14] N. M. Salim, "IMPROVEMENT OF THE GEOTECHNICAL PROPERTIES OF EXPANSIVE SOILS USING FLY ASH,” 2021.

[15] B. T. Wang, C. H. Zhang, X. L. Qiu, E. Y. Ji, and W. H. Zhang, "Research on wetting-drying cycles' effect on the physical and mechanical properties of expansive soil improved by OTAC-KCl," Adv. Mater. Sci. Eng., vol. 2015, 2015, doi: 10.1155/2015/304276.

[16] M. Hoy, R. Rachan, S. Horpibulsuk, A. Arulrajah, and M. Mirzababaei, "Effect of wetting-drying cycles on compressive strength and microstructure of recycled asphalt pavement - Fly ash geopolymer," Constr. Build. Mater., vol. 144, pp. 624-634, 2017, doi: 10.1016/j.conbuildmat.2017. 03.243 .

[17] J. Pooni, F. Giustozzi, D. Robert, S. Setunge, and B. O'Donnell, "Durability of enzyme stabilized expansive soil in road pavements subjected to moisture degradation," Transp. Geotech., vol. 21, no. June, p. 100255, 2019, doi: $10.1016 /$ j.trgeo.2019.100255.

[18] A. S. Muntohar, A. Widianti, E. Hartono, and W. Diana, "Engineering Properties of Silty Soil Stabilized with Lime and Rice Husk Ash and Reinforced with Waste Plastic Fiber," J. Mater. Civ. Eng., vol. 25, no. 9, pp. 1260-1270, 2013, doi: 10.1061/(asce)mt.1943-5533.0000659.

[19] ASTM, "American Standard for Testing and Materials (ASTM), D854, D2216, D6913, D4318, D698, and D2166," 1995.

[20] S. M. Rao and K. Revanasiddappa, "Influence of cyclic wetting drying on collapse behaviour of compacted residual soil," Geotech. Geol. Eng., vol. 24, no. 3, pp. 725-734, 2006, doi: 10.1007/s10706-004-5077-4.

[21] E. Kalkan, "Impact of wetting-drying cycles on swelling behavior of clayey soils modified by silica fume," Appl. Clay Sci., vol. 52, no. 4, pp. 345-352, 2011, doi: 10.1016/j.clay.2011.03.014
[22] Z. Saing and H. Djainal, "Effect of Lime Stabilization on Vertical Deformation of Laterite Halmahera Soil," IOP Conf. Ser. Earth Environ. Sci., vol. 140, no. 1, 2018, doi: 10.1088/1755-1315/140/1/012071.

[23] S. M. Rao, B. V. V. Reddy, and M. Muttharam, "The impact of cyclic wetting and drying on the swelling behaviour of stabilized expansive soils," Eng. Geol., vol. 60, no. 1-4, pp. 223-233, 2001, doi: 10.1016/S0013-7952(00)00103-4.

[24] S. R. Yang, H. Da Lin, J. H. S. Kung, and J. Y. Liao, "Shear wave velocity and suction of unsaturated soil using bender element and filter paper method," J. Geoengin., vol. 3, no. 2, pp. 67-74, 2008, doi: 10.6310/jog.2008.3(2).4.

[25] W. J. Likos and N. Lu, "Filter Paper Technique for Measuring Total Soil Suction," Transp. Res. Rec. J. Transp. Res. Board, vol. 1786, no. 1, pp. 120-128, 2002, doi: 10.3141/1786-14.

[26] R. Bulut and E. C. Leong, "Indirect measurement of suction," Geotech. Geol. Eng., vol. 26, no. 6, pp. 633-644, 2008, doi: 10.1007/s10706-008-9197-0.

[27] R. G. Fawcett and N. Collis-George, "A filter-paper method for determining the moisture characteristics of soil," Aust. J. Exp. Agric., vol. 7, no. 25, pp. 162-167, 1967, doi: 10.1071/EA9670162.

[28] S. Mani, L. G. Tabil, and S. Sokhansanj, "Effects of compressive force, particle size and moisture content on mechanical properties of biomass pellets from grasses," Biomass and Bioenergy, vol. 30, no. 7, pp. 648-654, 2006, doi: 10.1016/j.biombioe.2005.01.004.

[29] C. Ye, Z. Guo, C. Cai, J. Wang, and J. Deng, "Effect of water content, bulk density, and aggregate size on mechanical characteristics of Aquults soil blocks and aggregates from subtropical China," J. Soils Sediments, vol. 17, no. 1, pp. 210-219, 2017, doi: $10.1007 / \mathrm{s} 11368-016-1480-8$

[30] D. A. Laird, "Influence of layer charge on swelling of smectites," Appl. Clay Sci., vol. 34, no. 1-4, pp. 74-87, 2006, doi: 10.1016/j.clay.2006.01.009.

[31] K. Rasa, T. Eickhorst, R. Tippkötter, and M. Yli-Halla, "Structure and pore system in differently managed clayey surface soil as described by micromorphology and image analysis," Geoderma, vol. 173-174, pp. 10-18, 2012, doi: 10.1016/j.geoderma.2011.12.017.

[32] A. A. Fondjo, E. Theron, and R. P. Ray, "Semi-empirical model for predicting the swelling stress of compacted, unsaturated expansive soils," Civil Engineering and Architecture, vol. 9, no. 1, pp. 225-239, 2021, doi: 10.13189/cea.2021.090119.

[33] A. A. Fondjo and E. Theron, "Application of mathematical function to estimate the compaction characteristics of unsaturated soils," Civil Engineering and Architecture, vol. 9 , no. 1, pp. 255-262, 2021, doi: $10.13189 /$ cea.2021.090121. 